\title{
Administração pública no Brasil: reflexões sobre o campo de saber a partir da Divisão Acadêmica da Associação Nacional de Pós-Graduação e Pesquisa em Administração (2009-2013)*
}

\author{
Élvia Fadul \\ Universidade de Salvador (Unifacs) \\ Fernando de Souza Coelho \\ Universidade de São Paulo (USP) \\ Frederico Lustosa da Costa \\ Universidade Federal Fluminense (UFF) \\ Ricardo Corrêa Gomes \\ Universidade de Brasília (UnB)
}

\begin{abstract}
Este artigo nasceu de uma reflexão de membros do Comitê Científico da Divisão Acadêmica de Administração Pública da Associação Nacional de Pós-Graduação e Pesquisa em Administração (ANPAD) - a partir de seu trabalho no período de 2009 a 2012 - sobre o desenvolvimento desse campo de saber no Brasil. O texto descreve e analisa os fatores que influenciam a produção acadêmica em administração pública no país, destacando a sua significação como área no âmbito da ANPAD; o sistema de ensino, tanto em nível de graduação e de pós-graduação, como nas escolas de governo; e, finalmente, a organização dos grupos de pesquisa e de publicação científica (eventos e periódicos) que sustentam a investigação. Como resultado, o trabalho: (i) apresenta a trajetória da área de administração pública na ANPAD desde 1985 e sua agenda de pesquisa nos últimos anos; (ii) atualiza o panorama do ensino superior de administração pública no país, sobretudo dos programas de pós-graduação; e (iii) mapeia os congressos e revistas da área. Desse modo, o trabalho constitui per se um balanço sobre os avanços, as lacunas e os desafios do campo de saber da administração pública em nível nacional.
\end{abstract}

Palavras-chave: administração pública; Brasil; ANPAD; produção acadêmica; pós-graduação.

DOI: http://dx.doi.org/10.1590/0034-76122012

Artigo convidado recebido em 23 mar. 2014 e aceito em 7 jul. 2014.

* As ideias deste trabalho originaram-se de um Painel e de um Workshop da Divisão Acadêmica de Administração Pública realizados, respectivamente, no XXXV Encontro da ANPAD (EnANPAD) no Rio de Janeiro (2011) e no V Encontro de Administração Pública e Governo (EnAPG) em Salvador (2012). Os autores agradecem aos professores José Antonio Gomes de Pinho (EA-UFBA), José Francisco Salm (Esag-Udesc), Marta Ferreira Santos Farah (EAESPFGV) e Luciano Prates Junqueira (PUC-SP) pelas suas exposições no Painel, bem como à professora Mônica de Aguiar Mac-Allister da Silva (EA-UFBA) pela mediação do Workshop. Além desses pesquisadores, os autores agradecem aos líderes de tema e aos avaliadores da Divisão Acadêmica no quadriênio 2009-12; direta ou indiretamente, todos contribuíram para esta reflexão. 
Administración Pública en Brasil: reflexiones sobre el campo del saber a partir de la División Académica de la Asociación Nacional de Post-Grado e Investigación en Administración (2009-2013) Este artículo nació de una reflexión de los miembros del Comité Científico de la División Académica de Administración Pública de la Asociación Nacional de Post-Grado e Investigación en Administración (ANPAD) - a partir de su próprio trabajo en el período de 2009 a 2012 - sobre el desarrollo de este campo del saber em Brasil. El texto describe y analiza los factores que influencían la producción académica en administración pública en el país, destacando su significación como área en el ámbito de la ANPAD; el sistema de enseñanza, tanto a nível de grado como de post-grado, así como las escuelas de gobierno; y, finalmente, la organización de los grupos de investigación y de publicación científica (eventos y periódicos) que sustentan la investigación. Como resultado, el trabajo: (i) presenta la trayectoria de la área de administración pública en la ANPAD desde 1985 y la agenda de investigación para el campo en los últimos años; (ii) actualiza el panorama de la enseñanza superior de la administración pública en el país, sobre todo de los programas de post-grado; y (iii) mapea los congresos y revistas de la área. De este modo, el trabajo constituye per se un balance sobre los avanzes, las lagunas y los desafíos del campo del saber de la administración pública a nivel nacional.

Palabras clave: administración pública; Brasil; ANPAD; producción académica; post-grado.

Public Administration in Brazil: reflections on the field of knowledge from the Academic Division of the National Association of PostGraduate Studies and Research in Administration (2009-2013) This article was born of a reflection of members of the Scientific Committee of the Academic Division of Public Administration of the National Association of PostGraduate Studies and Research in Administration (ANPAD) - from his work in the period 2009 to 2012 — on the development of this field of knowledge in Brazil. The text describes and analyzes the factors that influence academic production in public administration in the country, highlighting its significance as an area within the ANPAD; debates around the education system, both at undergraduate and postgraduate, as in government schools, and finally, the organization of research groups and scientific publications (journals and events) that support research. As a result, the work: (i) shows the trajectory of the area of public administration in ANPAD since 1985 and research agenda for the field in last years, (ii) updated overview of higher education in the country of public administration mainly of graduate programs, and (iii) maps the conferences and journals in the field. Thus, the work itself constitutes a swing on progress, gaps and challenges of the field of knowledge of public administration at the national level.

Keywords: public administration; Brazil; ANPAD; academic production; graduate.

\section{Introdução}

A atual estrutura da ANPAD, do modo como foi definida a partir de 2009, vem contribuindo para que as suas divisões acadêmicas, baseadas em temas de interesse para a construção dos respectivos campos de saber em administração no país, estruturem, de maneira mais sistemática, a produção acadêmica de cada qual. Consciente desse propósito, a Divisão de Administração Pública (DAP), no quadriênio de 2009 a 2012, seguindo a orientação emanada 
pela Associação, desenvolveu um esforço no sentido de estabelecer algumas diretrizes para a pesquisa científica de tal campo submetida ao EnANPAD e ao EnAPG. ${ }^{1}$

Ressalta-se que essa empreitada não desconsidera toda a trajetória do campo de saber em administração pública no Brasil (APB), datada de quase um século, nem pretende minimizar a importância da produção acadêmica de estudiosos durante todo esse período. A intenção foi a de buscar novos elementos norteadores que fossem capazes de (re)estimular a construção do campo pela delimitação de objetos de pesquisa que conformassem um espaço próprio, típico das disciplinas autônomas.

Esta preocupação antiga e recorrente com o desenvolvimento do campo de saber em APB — ver Pacheco (2003) —, retomada pelo Comitê Científico da área na ANPAD, enseja, naturalmente, um balanço de acertos e erros, lições aprendidas e descobertas que são úteis para o seu desenvolvimento. Acredita-se, portanto, que devam ser compartilhados com a comunidade epistêmica. A partir da experiência de acompanhamento das submissões nos últimos cinco EnANPADs de uma quantidade substancial de trabalhos a cada ano (que ultrapassa os 3 mil incluindo-se os EnAPGs de 2010 e 2012), da análise do processo de avaliação, da montagem e coordenação das sessões e do acompanhamento das apresentações durante o congresso, considera-se pertinente registrar como a produção acadêmica de APB publicada pelos eventos da ANPAD se organizou nesse período.

Além dessas etapas preparatórias de organização e participação ativa nos encontros, as interlocuções ocorridas nas diversas oficinas e painéis da Divisão de APB nesses anos oportunizam uma reflexão que, para além da simples caracterização da produção acadêmica em AP na ANPAD, verse, também, sobre a sua institucionalização como campo de saber no país. As questões colocadas em discussão neste trabalho buscam, então, atualizar o debate sobre o campo de $\mathrm{APB}$, situando o seu estágio recente em vários aspectos.

Considera-se que alguns fatores têm influência — direta ou indireta — na determinação da produção acadêmica que, atualmente, os EnANPADs e os EnAPGs recebem em administração pública, quais sejam:

a) a significação da temática de APB no interior da própria ANPAD e sua agenda de pesquisa;

b) o sistema de ensino, tanto em nível de graduação e de pós-graduação, como nas escolas de governo; e,

c) a organização dos grupos de pesquisa e da publicação científica (eventos e periódicos) que sustentam a investigação em nível nacional.

A discussão inicia-se, assim, pela descrição das características da área de administração pública no interior da ANPAD desde a sua criação em 1985 (seção 1). Na sequência, a seção 3

\footnotetext{
${ }^{1} \mathrm{O}$ artigo, de acordo com o título, aborda o campo de saber em administração pública no Brasil a partir da Divisão Acadêmica da ANPAD no período 2009-13. Na verdade, o trabalho desse Comitê Científico abrangeu o quadriênio 2009-12. Sem embargo, algumas de suas formulações nesse ínterim, como a ampliação dos temas de interesse definida em novembro de 2012, foram implementadas em 2013, o que justifica o quinquênio.
} 
apresenta o panorama do ensino de pós-graduação em AP no Brasil e a seção 4, por sua vez, traz um overview sobre pesquisa e publicação nesse campo do saber. A seção 5 , à guisa de conclusão, realiza um balanço do status do campo de saber em administração pública no país.

\section{Características da área de administração pública na ANPAD}

De acordo com documentos da ANPAD e anais dos EnANPADs, a integração da administração pública como área para submissão de trabalho na Associação ocorreu em 1985, a partir da realização do IX EnANPAD no Rio de Janeiro. Nesse Encontro a área foi denominada de Política e Negócios Públicos - tal como a acepção de Public Affairs em língua inglesa - e teve tão somente três trabalhos apresentados. Em 1987, no XI EnANPAD realizado em Belo Horizonte, a denominação da área foi alterada para Administração Pública e somou 35 artigos apresentados. Essa denominação foi mantida até o ano 2000, período em que a área recebia em torno de 150 artigos para avaliação. Nos Anais do EnANPAD do ano de 2000 - XXIV edição — o coordenador da área de AP, professor Fernando G. Tenório (EBAP/FGV-RJ), afirmava que: "Dos 160 trabalhos que foram apresentados à área de Administração Pública, problemas de formatação fizeram com que somente 127 fossem aceitos para avaliação. (...) O número de artigos selecionados para apresentação foi de 40" (Anais do XXIV EnANPAD, 2000:69).

Saliente-se que, entre meados dos anos de 1980 e o final da década de 1990, embora crescessem os programas de mestrado e doutorado em administração no Brasil, ${ }^{2}$ as linhas de pesquisa em AP eram diminutas, destacando-se as escolas que encetaram o ensino de administração pública no país em nível de pós-graduação stricto sensu, a saber: a EBAP/FGV-RJ, a EAESP/FGV-SP, o NPGA-UFBA, o PPGA-UFRGS e o PPGA-UnB.

A partir de meados dos anos 1990, no bojo da reforma do aparelho do Estado no Brasil e com a ampliação das políticas públicas advindas dos direitos sociais da Constituição Federal de 1988, o objeto de estudo da administração pública entrou na agenda de pesquisa de estudiosos que não eram - tradicionalmente - do campo de saber e/ou de programas de pós-graduação em AP, o que elevou, significativamente, a cada ano, o número de submissões de artigos para esta área nos EnANPADs. O quadro 1 organiza as informações da área de administração pública nos EnANPADs entre o seu surgimento em 1985 e o ano de 2000.

Em 2001, em decorrência dessa ampliação da área de AP nos anos anteriores e de uma percepção de que a subárea de políticas públicas crescia em importância, ocorreu sua divisão em duas subáreas: Gestão Pública e Governança (GPG) e Políticas Públicas (POP). Essas duas subáreas funcionariam, no quadriênio 2001-04, separadamente. Os anais do XXV EnANPAD, sediado em Campinas (SP) em 2001, mostram, por exemplo, que a área de GPG recebeu 93 trabalhos e aprovou 35, enquanto a área de POP contabilizou 71 submissões, com 25 artigos selecionados.

\footnotetext{
${ }^{2}$ No ano 2000, o país tinha em torno de 40 cursos de mestrado e 10 de doutorado em administração, em comparação aos seis programas de mestrado que fundaram a ANPAD em 1976 (Anais EnANPAD, 2001:5).
} 
Quadro 1

Evolução da área de administração pública da ANPAD (1985-2000)

\begin{tabular}{|c|c|c|c|}
\hline Ano & Nomenclatura da Área & Coordenador da Área & $\begin{array}{c}\text { № Trabalhos } \\
\text { (apresentados) }\end{array}$ \\
\hline 1985 & Política e Negócios Públicos & José C. Castanhar (EBAP/FGV) & 3 \\
\hline 1986 & Política e Negócios Públicos & $*_{\text {sem }}$ registro & *sem registro \\
\hline 1987 & Administração Pública & José C. Castanhar (EBAP/FGV) & 35 \\
\hline 1988 & Administração Pública & Bianor S. Cavalcanti (EBAP/FGV) & 14 \\
\hline 1989 & Administração Pública & Celina M. de Souza (NPGA/UFBA) & 24 \\
\hline 1990 & Administração Pública & Celina M. de Souza (NPGA/UFBA) & 14 \\
\hline 1991 & Administração Pública & Bianor S. Cavalcanti (EBAP/FGV) & 21 \\
\hline 1992 & Administração Pública & Enrique Saraiva (EBAP/FGV) & 16 \\
\hline 1993 & Administração Pública & José A. G. Pinho (NPGA/UFBA) & 25 \\
\hline 1994 & Administração Pública & José A. G. Pinho (NPGA/UFBA) & 21 \\
\hline 1995 & Administração Pública & Marta F. S. Farah (EAESP/FGV) & 21 \\
\hline 1996 & Administração Pública & Marta F. S. Farah (EAESP/FGV) & 33 \\
\hline 1997 & Administração Pública & Élvia Fadul (NPGA/UFBA) & 28 \\
\hline 1998 & Administração Pública & Élvia Fadul (NPGA/UFBA) & 39 \\
\hline 1999 & Administração Pública & Fernando G. Tenório (EBAP/FGV) & 40 \\
\hline 2000 & Administração Pública & Fernando G. Tenório (EBAP/FGV) & 41 \\
\hline
\end{tabular}

Fonte: Elaboração própria, baseada nos Anais dos EnANDAPs - IX ao XXIV.

*De acordo com Fachin (2006), no ano de 1986 a ANPAD não publicou os anais do evento.

Em 2004, dentro de sua política de criar eventos específicos com periodicidade bianual, a ANPAD organizou o I EnAPG, realizado no Rio de Janeiro. Em sua primeira edição esse evento recebeu 366 trabalhos (submissão) em um contexto de surgimento de novos programas de pós-graduação (ex.: doutorado em AP da EAESP-FGV e mestrado em AP da FJP-MG) e do despertar de pesquisadores de outras especialidades da administração por alguns objetos de estudo da AP.

Ainda que o número de trabalhos aumentasse expressivamente, já era perceptível, desde meados dos anos 2000, que boa parte desses novos artigos que chegavam às áreas de GPG e POP apenas tangenciava a AP como objeto de estudo, não se utilizando de uma abordagem de administração pública. Muitos dos autores eram, na verdade, visitantes com algum interesse no tema, o que ocasionava — visivelmente - uma fragmentação do campo de saber, marcado nas palavras de Pacheco (2003:65) por "um vale tudo temático".

Em 2005, a ANPAD criou a estrutura de Divisões Acadêmicas e a área foi renomeada para Administração Pública e Gestão Social (APS). Tinha três subdivisões: Estado, Administração Pública e Sociedade Civil (APS-A); Gestão e Políticas Públicas (APS-B) e Gestão Social e Am- 
biental (APS-C). Contudo, a estrutura da área (então divisão acadêmica) não facilitou um delineamento do campo de saber em AP no âmbito da ANPAD. As ementas das subdivisões, por exemplo, se sobrepunham; não havia uma distinção entre os temas tratados nas subdivisões APS-A e APS-B. Qualquer dos trabalhos apresentados poderia ser enquadrado em qualquer dessas duas subáreas. Em adição, a inserção da subdivisão de APS-C na Divisão Acadêmica de APS ampliou seu locus, desconfigurando-a. ${ }^{3}$ Nessa subdivisão, por exemplo, não se percebia consistência na abordagem dada à gestão socioambiental, sem aderência com a administração pública. Muitos dos artigos tratavam de responsabilidade social corporativa ou sustentabilidade organizacional, sem relação com as bases teóricas e epistemológicas do campo de saber em administração pública.

Com tal amplitude, no triênio 2006-08 a divisão acadêmica de APS foi a que mais recebeu trabalhos nos EnANPADs - em média, 500 artigos por evento, incluindo os EnAPGs de 2006 e 2008. Mais uma vez, percebia-se o aumento da submissão de artigos sem aderência com as pesquisas de AP, urgindo o (re)pensar da demarcação desse campo de saber na ANPAD. O quadro 2 sintetiza as informações da área de administração pública nos EnANPADs entre 2001 e 2008, período de subdivisão da área e surgimento do EnAPG.

Quadro 2

Evolução da área de administração pública da ANPAD (2001-08)

\begin{tabular}{|c|c|c|c|c|}
\hline \multicolumn{5}{|c|}{ Período 2001-04 / Administração pública dividida em duas áreas - CPG e POP } \\
\hline Ano & Áreas de Adm. Pública & Coordenador & № Submissão & № Apresentados \\
\hline \multirow{2}{*}{2001} & Gestão Pública e Governança & Deborah M. Zouain (EBAP/FGV) & 93 & 35 \\
\hline & Políticas Públicas & George Avelino Filho (EAESP/FGV) & 71 & 25 \\
\hline \multirow{2}{*}{2002} & Gestão Pública e Governança & Deborah M. Zouain (EBAP/FGV) & 124 & 38 \\
\hline & Políticas Públicas & George Avelino Filho (EAESP/FGV) & 77 & 27 \\
\hline \multirow{2}{*}{2003} & Gestão Pública e Governança & Luciano P. Junqueira (PUC/SP) & 96 & 32 \\
\hline & Políticas Públicas & José Matias Pereira (PPGA/UNB) & 87 & 38 \\
\hline \multirow{2}{*}{2004} & Gestão Pública e Governança & Luciano P. Junqueira (PUC/SP) & 173 & 47 \\
\hline & Políticas Públicas & José Matias Pereira (PPGA/UNB) & 113 & 40 \\
\hline
\end{tabular}

Continua

\footnotetext{
${ }^{3}$ Vale mencionar que a área de Gestão Social e Ambiental (GSA) foi criada pela ANPAD em 2003 e funcionou de maneira independente como uma das 17 áreas dos EnANPADs de 2003 e 2004. Em 2005, com o movimento da Associação de (re)organização para uma estrutura de divisões, as então 17 áreas foram fundidas em 10 divisões acadêmicas. Assim, a área de GSA foi, errônea e artificialmente, acoplada às áreas de Gestão Pública e Governança (GPG) e Políticas Públicas (POP) criadas em 2001, resultando em uma inchada, descaracterizada e sem identidade divisão acadêmica de Administração Pública e Gestão Social (APS).
} 


\begin{tabular}{|c|c|c|c|c|}
\hline \multicolumn{5}{|c|}{ Período 2005-08 / Administração pública e gestão social (APS) dividida em três subáreas } \\
\hline \multirow[t]{3}{*}{ Ano } & Subdivisões de APS & Coordenadores & № Submissão & № Apresentados \\
\hline & Estado, AP e Soc. Civil (APS-A) & Marco A. Ruediger (EBAPE/FGV) & 128 & 36 \\
\hline & Gestão e Pol. Públicas (APS-B) & Élvia Fadul (NPGA/UFBA) & 153 & 40 \\
\hline \multirow[t]{4}{*}{2005} & $\begin{array}{l}\text { Gestão Social e Ambiental } \\
\text { (APS-C) }\end{array}$ & Luis F. Nascimento (PPGA/UFRGS) & 194 & 51 \\
\hline & Divisão & José A. G. Pinho (NPGA/UFBA) & 475 & 127 \\
\hline & Estado, AP e Soc. Civil (APS-A) & Deborah M. Zouain (EBAPE/FGV) & 143 & 37 \\
\hline & Gestão e Pol. Públicas (APS-B) & Élvia Fadul (NPGA/UFBA) & 168 & 44 \\
\hline \multirow[t]{4}{*}{2006} & $\begin{array}{l}\text { Gestão Social e Ambiental } \\
\text { (APS-C) }\end{array}$ & Luis F. Nascimento (PPGA/UFRGS) & 215 & 54 \\
\hline & Divisão & José A. G. Pinho (NPGA/UFBA) & 526 & 135 \\
\hline & Estado, AP e Soc. Civil (APS-A) & Deborah M. Zouain (EBAPE/FGV) & 177 & 54 \\
\hline & Gestão e Pol. Públicas (APS-B) & Élvia Fadul (NPGA/UFBA-Unifacs) & 151 & 45 \\
\hline \multirow[t]{4}{*}{2007} & $\begin{array}{l}\text { Gestão Social e Ambiental } \\
\text { (APS-C) }\end{array}$ & Luis F. Nascimento (PPGA/UFRGS) & 189 & 56 \\
\hline & Divisão & José A. G. Pinho (NPGA/UFBA) & 517 & 155 \\
\hline & Estado, AP e Soc. Civil (APS-A) & Deborah M. Zouain (EBAPE/FGV) & 135 & 47 \\
\hline & Gestão e Pol. Públicas (APS-B) & Élvia Fadul (NPGA/UFBA-Unifacs) & 167 & 54 \\
\hline \multirow[t]{3}{*}{2008} & $\begin{array}{l}\text { Gestão Social e Ambiental } \\
\text { (APS-C) }\end{array}$ & Luis F. Nascimento (PPGA/UFRGS) & 174 & 57 \\
\hline & Divisão & José A. G. Pinho (NPGA/UFBA) & 476 & 158 \\
\hline & \multicolumn{4}{|c|}{ EnAPGs - criado em 2004 e com periodicidade bianual } \\
\hline Ano & Evento & Coordenador & № Submissão & № Apresentados \\
\hline 2004 & I EnAPG & George Avelino Filho (EAESP/FGV) & 366 & 107 \\
\hline 2006 & II EnAPG & José A. G. Pinho (NPGA/UFBA) & 410 & 146 \\
\hline 2008 & III EnAPG & José A. G. Pinho (NPGA/UFBA) & 570 & 176 \\
\hline
\end{tabular}

Fonte: Elaboração própria, baseada nos Anais dos EnANPADs (XXV-XXXII) e EnAPGs (I-III).

Em 2009, a ANPAD transformou a lógica de organização e de funcionamento das divisões acadêmicas: eliminou as subdivisões e definiu temas de interesse para a sua estruturação. Essa Divisão Acadêmica manteve a denominação de Administração Pública e Gestão Social (APS) e para a submissão de trabalhos científicos foram indicados 11 temas de interesse, além dos temas livres. Para a definição desses temas de interesse, foi realizado 
pelo Comitê Científico um levantamento dos programas filiados à ANPAD, identificando aqueles que tinham áreas de concentração e/ou linhas de pesquisa em administração pública. Uma vez identificadas as orientações dos mestrados e doutorados que se voltavam para a administração pública, delinearam-se os temas de interesse em conformidade com seus objetos de estudo.

No ano de 2010, por solicitação do Comitê Científico, a Divisão Acadêmica voltou a ser denominada novamente e tão somente de Administração Pública (APB). O objetivo do Comitê Científico, com esta decisão, foi (re)discutir a especificidade e (re)construir uma identidade desse campo de saber na ANPAD, reunindo a pesquisa científica oriunda da comunidade epistêmica de administração pública. A lógica de estruturação das Divisões Acadêmicas por temas de interesse foi mantida, mas o Comitê Científico realizou ajustes na enunciação e nos descritores de cada tema, reorganizando os 11 temas anteriores em oito, almejando clareza na sua apresentação. A partir de 2011, os oito temas de interesse que estruturaram a Divisão Acadêmica foram definidos para abarcarem a produção de conhecimento tipicamente da área de AP.

Na redefinição desses temas de interesse levou-se em consideração que a investigação em administração pública não se restringe aos estudos da gestão de organizações governamentais e/ou das ações do setor público, mas envolve conceitos e aplicações relacionados com o Estado e à sociedade civil. A partir dessa dimensão - Estado e sociedade - que conforma o espaço público, alguns temas de interesse foram estruturados em torno do objeto Estado: papéis, estratégias, estruturas, atores, processos, relações e poder, e das suas transformações a partir de crises e reformas.

A segunda dimensão procurou privilegiar temas de interesse relacionados com as políticas públicas. Essa dimensão aborda questões relativas aos processos de políticas públicas e setores de intervenção: econômicos, sociais, da infraestrutura, administrativos. Privilegia a análise de políticas públicas pela agenda, processo decisório, formulação, implementação, monitoramento e avaliação de programas governamentais e as novas abordagens em políticas públicas. Em adição, tal dimensão envolve os temas de interesse relacionados com a repartição de encargos e recursos entre esferas de governo, descentralização e territorialidade, bem como os novos arranjos institucionais intergovernamentais.

A terceira dimensão trata especificamente da administração pública, considerando os aspectos extra e intraorganizacionais. Nos aspectos externos às organizações públicas, essa dimensão abarca a gestão e a regulação de serviços públicos em setores específicos, os modos de provisão desses serviços e o novo pluralismo organizacional do setor público tais como organizações sociais, parcerias público-privadas, agências executivas, agências reguladoras entre outros. No que tange aos aspectos intraorganizacionais, pensou-se nas discussões acerca das funções gerenciais das organizações públicas tais como planejamento, organização, direção e liderança, coordenação e controle; e áreas funcionais: gestão de pessoas; gestão de materiais e patrimônio; logística e suprimentos; gestão financeira; gestão de processos e sistemas de informações gerenciais; informática pública e governo eletrônico; cultura organizacional; comunicação e marketing no setor público. Nessa dimensão incluem-se, ainda, temas relativos 
ao processo de planejamento e orçamento governamental; finanças públicas: tributação/arrecadação, gasto público e financiamento; controle interno e externo; políticas, formas e mecanismos relacionados com transparência, prestação de contas, accountability, responsabilidade fiscal; combate à corrupção e gestão por resultados.

Ademais, a Divisão organizou dois temas de interesse que ultrapassam, mas permeiam essas dimensões. O primeiro visa à discussão em torno do desenvolvimento da administração pública como campo de saber, tratando de seus fundamentos teóricos e das suas perspectivas metodológicas. O segundo volta-se para os estudos sobre história e a memória da administração pública no Estado brasileiro, incluindo a construção de agendas de pesquisa e avaliação da produção científica na área.

Com essas modificações, foi possível perceber nos EnANPADs de 2010, 2011 e 2012 a diminuição do número de artigos submetidos à divisão acadêmica (quadro 3) e a queda do enquadramento de trabalhos em temas livres, bem como notar o deslocamento de trabalhos que até então eram encaminhados para APB — por tratarem da AP apenas pelo objeto — para outras divisões da ANPAD mais adequadas, quando a base teórica e/ou epistemológica não pertencia ao campo de saber. Nesse período, observou-se também uma melhoria sensível do processo de avaliação dos artigos, com a compatibilização entre a especialidade dos avaliadores e os descritores dos temas de interesse. Esses aperfeiçoamentos permitiram a Divisão Acadêmica de APB ser agraciada com o Prêmio de Melhor Divisão da ANPAD de 2011.

Quadro 3

Evolução da área de administração pública da ANPAD (2009-13)

\begin{tabular}{|c|c|c|c|c|}
\hline \multicolumn{5}{|c|}{ Período 2009-13 / Administração Pública dividida em Temas de Interesse } \\
\hline Ano & Nomenclatura da Área & Coordenador & $\begin{array}{c}\text { № } \\
\text { Submissão }\end{array}$ & $\begin{array}{c}\text { № } \\
\text { Apresentados }\end{array}$ \\
\hline 2009 & $\begin{array}{l}\text { Administração Pública e Gestão Social } \\
\text { (11 temas) }\end{array}$ & Élvia Fadul (Unifacs e NPGA/UFBA) & 395 & 119 \\
\hline 2010 & Administração Pública (oito temas) & Élvia Fadul (Unifacs e NPGA/UFBA) & 342 & 106 \\
\hline 2011 & Administração Pública (oito temas) & Élvia Fadul (Unifacs e NPGA/UFBA) & 352 & 134 \\
\hline 2012 & Administração Pública (oito temas) & Élvia Fadul (Unifacs e NPGA/UFBA) & 341 & 121 \\
\hline 2013 & Administração Pública ( 11 temas) & Ricardo C. Gomes (PPGA/UNB) & 353 & 138 \\
\hline \multicolumn{5}{|c|}{ En APGs - nomenclatura em 2012 alterada para Administração Pública e Governo } \\
\hline Ano & Evento & Coordenador & $\begin{array}{c}\text { № } \\
\text { Submissão }\end{array}$ & $\begin{array}{c}\text { № } \\
\text { Apresentados }\end{array}$ \\
\hline 2010 & IV EnAPG & Élvia Fadul (Unifacs e NPGA/UFBA) & 509 & 149 \\
\hline 2012 & V EnAPG & Élvia Fadul (Unifacs e NPGA/UFBA) & 510 & 160 \\
\hline
\end{tabular}

Fonte: Elaboração própria, baseada nos Anais dos EnANPADs (XXXIII-XXXVII) e EnAPGs (IV-V). 
Na mesma direção de demarcação do campo de saber em AP, em 2011 o Comitê Científico de APB obteve a aprovação da Diretoria da ANPAD para alterar o nome do EnAPG a partir de sua V edição (2012), de Encontro de Administração Pública e Governança para Encontro de Administração Pública e Governo. Entre o I e o IV EnAPG, o termo Governança provocava a interpretação errônea da comunidade de administração de que quaisquer artigos sobre Governança Corporativa (que é distinta do conceito de Governança no Setor Público) eram condizentes com o evento.

No ano de 2013, os 8 temas de interesse que vigoraram no triênio 2010-12 foram ampliados, novamente, para 11 temas de interesse, ${ }^{4}$ tal como em 2009. Optou-se pela subdivisão dos três temas que concentravam 50\% da submissão, a saber: do tema de interesse Estado, Governo e Administração Pública derivou o tema Relações entre Estado e Sociedade; do tema de interesse Análise de Políticas Públicas concebeu-se o tema Caso e Aplicações em Políticas Públicas; e o tema de interesse sobre Gerenciamento em Organizações Públicas foi desdobrado em Funções Gerenciais e Áreas Funcionais I e II.

Fundamentalmente, tratou-se de um ajuste para desconcentrar os trabalhos entre os temas de interesse e, por conseguinte, equalizar o processo de avaliação. Pela manutenção do número médio de artigos submetidos à APB no EnANPAD 2013 em comparação com o triênio 2010-12 (quadro 3), o aumento de oito para 11 temas de interesse atingiu o objetivo de redistribuição dos textos pela divisão acadêmica. E, ao menos nesse primeiro ano, o efeito chamariz de recebimento de mais artigos sem aderência com a AP, devido à criação de três novos temas, não foi notado.

No caso do tema de interesse Estado, Governo e Administração Pública, cabia subdividir os artigos que analisavam o "Estado por dentro" - com ênfase na máquina governamental e nos condicionantes administrativo-institucionais - dos trabalhos que abordavam o Estado em uma perspectiva sociocêntrica e/ou de interpenetração com as organizações da sociedade civil. No caso do tema de Análise de Políticas Públicas, diante da heterogeneidade dos textos, explicada pelo aumento da apropriação e do uso do termo políticas públicas pela academia de administração, urgia dividi-lo em dois temas: um mais voltado à tradição da corrente da public policy analisys, com contribuições, sobretudo, da ciência política considerando sua intersecção com a AP; e outro de design amplo e de caráter aplicado que congregue as investigações multidisciplinares e os estudos de caso sobre políticas, programas e projetos públicos. Ademais, considerando o distanciamento histórico dos campos do saber de administração pública e de políticas públicas no Brasil, descrito por Farah (2011), acredita-se que a proposição de um tema de interesse específico sobre public policy analisys atraia os pesquisadores de políticas públicas que se localizam na comunidade epistêmica de ciência política, representadas pela Anpocs e ABCP, para um debate interdisciplinar com a área de administração pública da ANPAD.

\footnotetext{
${ }^{4}$ Uma apresentação dos 11 temas da Divisão Acadêmica de APB, com seus respectivos descritores, está disponível em: <www.anpad.org.br/diversos2/divisoes_academicas/2014/apb_lideres.html>.
} 
No caso do desdobramento do tema de interesse sobre Gerenciamento em Organizações Públicas levou-se em conta, também, um maior espaço na divisão acadêmica para a interação entre os objetos de estudos de algumas áreas funcionais da administração (como recursos humanos, marketing, operações/logística e sistemas de informação) com a ambiência das organizações públicas. Na última década, esses estudos tiveram pouca incidência na literatura nacional, o que se explica pela subvalorização do focus organizacional vis-à-vis as agendas de pesquisa macroestruturais em torno das transformações do papel do Estado e das reformas da administração pública.

Em suma, com essa reestruturação no quadriênio 2009-12 levada a cabo pelo Comitê Científico, com implicações tanto nesse período como para o biênio 2013-14, a expectativa é que a explosão quantitativa de trabalhos averiguada na Divisão Acadêmica de APB (e suas variantes) na ANPAD na década de 2000, nos anos vindouros seja ajustada qualitativamente para uma produção acadêmica mais condizente com o campo de saber em AP, colaborando com a construção de sua identidade no seio da Associação e com uma maior cumulatividade de conhecimento na área.

Igualmente, espera-se que o Comitê Científico reestruture, periodicamente, os temas de interesse, incorporando a agenda de pesquisa emergente. Ilustrativamente, na atualidade, segundo Lustosa da Costa (2010), entre as novas e/ou incipientes questões a serem estimuladas na produção acadêmica em administração pública no país estão: a (re)politização dos modelos de gestão pública, a governança democrática e a incorporação da cidadania, a ressignificação do papel da administração pública para o desenvolvimento, a implementação das políticas públicas (service delivery) e a gestão pública intersetorial.

Na sequência, as seções 3 e 4 sumarizam, respectivamente, o panorama da educação superior em administração pública no Brasil e seu sistema de pesquisa, eventos e publicação, cujas institucionalidades se interpenetram com a produção acadêmica desse campo de saber.

\section{0 panorama da educação superior em administração pública no Brasil}

A educação superior em administração pública desembarcou no Brasil nos anos 1950, a partir da influência da assistência técnica norte-americana, com a implantação de cursos de graduação e centros de pesquisa (ex.: FGV-RJ) no bojo do processo de ampliação de um Estado administrativo - desde o Estado Novo - e dos ideais desenvolvimentistas do pós-guerra. Os primeiros cursos de graduação em AP surgem nos anos 1950 (Coelho e Nicolini, 2013). E, entre o final da década de 1960 e o início de 1970, surgem os primeiros cursos de mestrado e/ou áreas de concentração em administração pública nos programas de pós-graduação em administração no Brasil, destacando-se, segundo Fischer (1984), a Escola Brasileira de Administração Pública (EBAP) da FGV-RJ, a Universidade Federal da Bahia (UFBA) e a Universidade Federal do Rio Grande do Sul (UFRGS). 
Até a metade do século XX nos Estados Unidos (e até o limiar de 1980 no Brasil), o campo de saber em administração pública concebia a gestão/gerência pública — nos moldes weberianos - como o locus de execução pela burocracia das políticas definidas pelos mandatários políticos. Complementavam tal concepção, no Brasil, a tradição secular do direito administrativo (law oriented) herdada dos nossos colonizadores ibéricos e os estudos que se avolumaram com o Estado Desenvolvimentista que relacionavam o binômio planejamento governamental e crescimento econômico.

Nos Estados Unidos, enquanto no pós-1950 a abordagem da análise de políticas públicas (advinda da ciência política) se integrava à gestão pública, minimizando a dicotomia política-administração, no Brasil, contrariamente, o autoritarismo (1964-85) sobrevalorizou a tecnologia administrativa na gestão pública, desprezando as pesquisas sobre os atores/ interesses e cultura/instituições políticas. Contribui — sobremaneira — para tal panorama a vinculação (ou subordinação) institucional da formação acadêmica em administração pública à de administração de empresas no país, que diluiu a especificidade da administração pública e corroborou para o seu subdesenvolvimento disciplinar em nível nacional. Resultado: em 1982, 30 anos após a instalação do primeiro curso de graduação em administração pública no Brasil e 15 anos após a implantação do primeiro programa de mestrado em tal área, o Brasil tinha tão somente cinco cursos de graduação em administração pública e três programas de mestrado (ou áreas de concentração), com destaque para a EAESP/FGV-SP na graduação e para a EBAP/FGV-RJ no mestrado (Coelho e Nicolini, 2013).

A partir de meados dos anos 1980, a administração pública nacional, despida da política e identificada como management outrora, reformular-se-ia como campo de saber e diante da redemocratização e das transformações do papel do Estado. Como campo de saber, a AP no pós-1980, ainda que fragmentada, paulatinamente, apoiar-se-ia em um focus políticoorganizacional, desatando-se do focus puramente administrativo; tentava-se remover ou, no mínimo, abrandar a dicotomia política-administração com uma interpenetração entre a ciência política e os estudos organizacionais, consoante com a repolitização caracterizada pelos conflitos de interesses, pela competição político-eleitoral e pelo controle social do setor público (Mezzomo Keinert, 2000; Coelho, Olenscki e Celso, 2011).

Nos anos de 1990, sobretudo no pós-1995, com os desdobramentos do binômio descentralização-democratização advindos da Constituição Federal de 1988 e o processo de Reforma do Estado, as pesquisas em administração pública como descrito na seção 2 cresceram no país. Vários grupos de pesquisa foram criados e cadastrados no $\mathrm{CNPq}$, coorganizados, sobretudo, por pesquisadores das áreas de conhecimento em administração e ciências sociais. Contudo, esse aumento da produção acadêmica doméstica no campo de saber não ocasionou — institucionalmente - o surgimento de programas específicos de mestrado e doutorado em administração pública ou correlatos (gestão pública, gestão de políticas públicas e políticas públicas) no sistema de pós-graduação nacional.

A partir de meados da década de 2000, verifica-se o aumento da quantidade de cursos de graduação — bacharelados e tecnológicos — em administração pública e similares no 
país (Coelho, 2008). Grosso modo, com a expansão das universidades federais com o Reuni e a conformação de um espaço público ampliado no Brasil (Estado Rede), abriu-se uma janela de oportunidade de natureza acadêmica e profissional que oportunizou a criação de novos cursos e o renascer da educação superior em administração pública. Surgiram cursos de gestão de políticas públicas ou similares (gestão pública, políticas públicas e gestão social) - tais como os ofertados pela USP, Unicamp, UnB, UFRN, UFABC, UFMG, UFRGS, UFPR, UFRJ e Ufca - que são bacharelados ou tecnológicos (como os da Ufba, UFPB e UFCG) interdisciplinares que almejam uma formação acadêmica tecnopolítica. Esses cursos e os de administração pública (tais como os ofertados pela FGV-SP, Unesp, EG-FJP, Udesc, UFF, UFRRJ, Ufla, Unifal, Ufal, Unilab), atualmente, somam cerca de 50 graduações no país, considerando tão somente a oferta de instituições de educação superior (IES) públicas e na modalidade presencial. ${ }^{5}$ Diante desse movimento de expansão, intitulado por coordenadores e professores como Campo de Públicas, o Conselho Nacional de Educação (CNE) institui em 2014 as Diretrizes Curriculares Nacionais (DCNs) para os cursos de graduação em administração pública e correlatos no país, reconhecendo sua identidade própria no que se refere à formação acadêmica. Para o CNE, pela Resolução no 1 , de 13 de janeiro de 2014, ficam instituídas as DCNs do curso de graduação em AP “(...) que compreendem o campo multidisciplinar de investigação e atuação profissional voltado ao Estado, ao Governo, à Administração Pública e Políticas Públicas, à Gestão Pública, à Gestão Social e à Gestão de Políticas Públicas" (art. 1ํ, p. 1).

Em nível de pós-graduação, a oferta de cursos de mestrado e doutorado em administração pública, embora crescente nos últimos cinco anos, ainda não é condizente com a amplitude e a diversidade do setor público no país. Observa-se o surgimento de alguns cursos de mestrado - tanto acadêmicos como profissionais - em administração pública na área de avaliação de administração da Capes, bem como alguns cursos de mestrado e doutorado em Gestão/Políticas Pública(s) em outras áreas de avaliação como: interdisciplinar, ciência política, planejamento urbano e regional, serviço social, economia e sociologia.

$\mathrm{Na}$ área de avaliação de administração, a qual inclui ciências contábeis e abriga as pós-graduações associadas à ANPAD, de acordo com o quadro 4, há a oferta de um curso de doutorado (FGV-SP), três cursos de mestrado acadêmico (FGV-SP, FJP e USP) e 10 cursos de mestrado profissional que se apresentam como programas - exclusivamente - de administração/gestão pública. Ainda, se levarmos em conta os mestrados e doutorados em administração que têm área de concentração ou linha de pesquisa em administração pública, totalizam-se 20 programas nesse campo de saber.

\footnotetext{
${ }^{5}$ Para um quadro sinóptico bastante atual dos cursos de graduação — bacharelado e tecnológico — em administração pública e similares ofertados no país na modalidade presencial, ver a tese de doutorado de Vendramini (2013: 90-93). Adicionalmente, é importante registrar a existência de mais de 40 graduações em administração pública na modalidade a distância, muitas das quais ofertadas por universidades públicas, por meio do Sistema da Universidade Aberta do Brasil (UAB) e com o apoio do Programa Nacional de Formação em Administração Pública (Pnap) da Capes.
} 


\section{Programas de pós-graduação stricto sensu em administração pública e cursos de mestrado e doutorado em administração que apresentam relação com administração pública, em 2014}

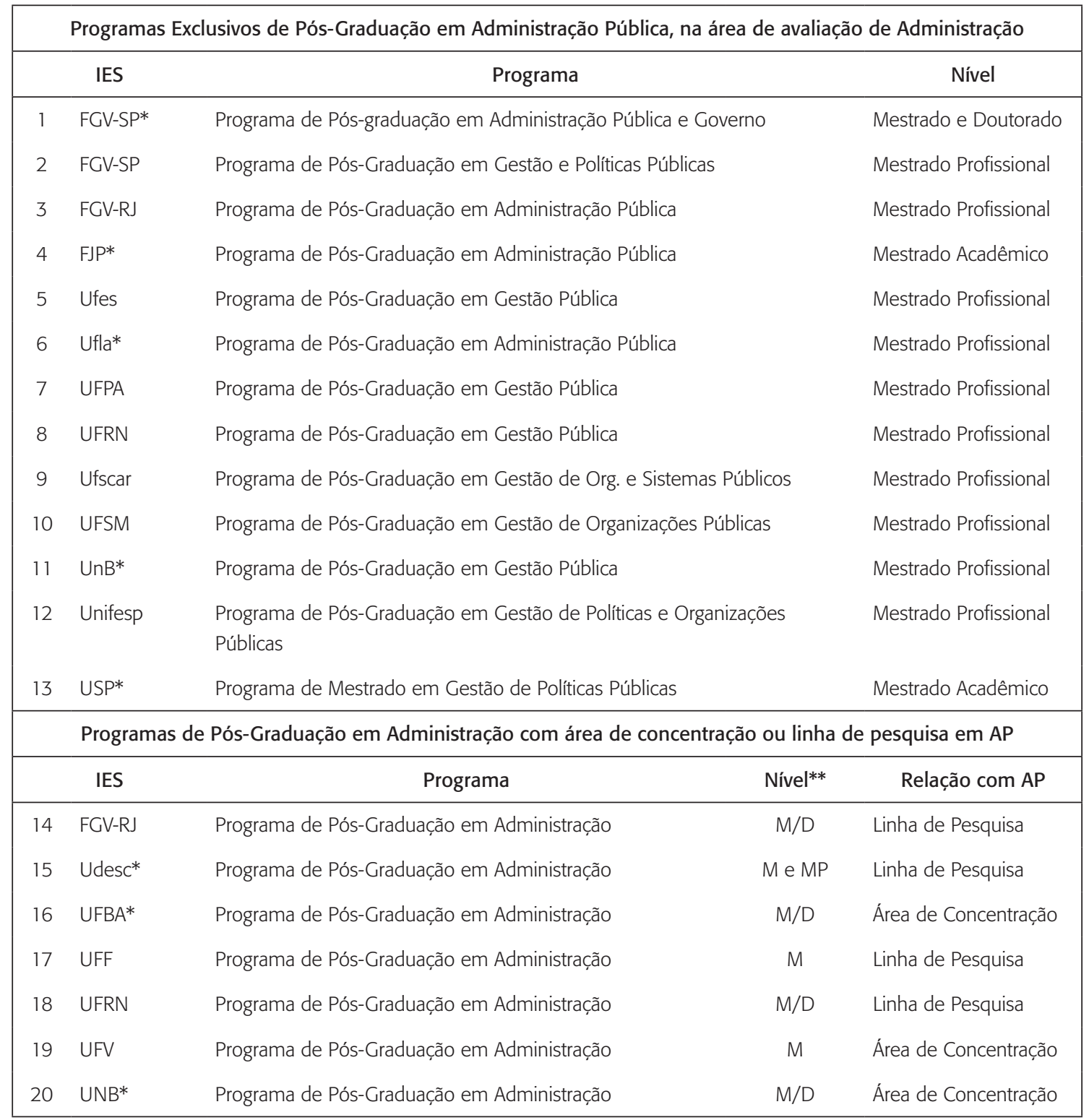

Fonte: Elaboração própria, baseada na relação dos cursos recomendados pela Capes na área de avaliação de Administração e Ciências Contábeis (2014).

* Essas IES ofertam também cursos de graduação exclusivos em AP ou similares.

** $M / D=$ Mestrado e Doutorado; $M=$ Mestrado Acadêmico e MP = Mestrado Profissional. 
Entre os programas de administração/gestão pública, o mais antigo é o da FGV-SP; o curso de mestrado iniciou em 1985 e o de doutorado — único no país até então — abriu em 2002. Alguns programas de pós-graduação que outrora eram de administração pública, ofertados por IES que fundaram o ensino superior nesse campo de saber em nível nacional, tiveram seus cursos de mestrado e doutorado reorientados na última década. A EBAP/FGV, cujo curso de mestrado em Administração Pública inaugurou no Brasil a pós-graduação stricto sensu em administração em 1967, foi reposicionada como EBAPE/FGV em 2002, acrescentando o E de Empresas. A EAUFBA, tradicional no ensino e pesquisa em gestão pública; igualmente, ampliou suas linhas de pesquisa e ressignificou seu programa de pós-graduação em administração para além da Administração Pública. Espera-se que essa descaracterização da administração pública nessas escolas tradicionais não desestimule as ideias/projetos de programas de pós-graduações do tipo puro sangue em administração pública nessa área da Capes. ${ }^{6}$ Nesse sentido, é animador assistir ao nascimento recente de alguns cursos de pósgraduação em administração pública derivados da implementação do ensino de graduação na área alguns anos atrás, tal como se nota na USP e na Ufla.

De qualquer modo, embora a criação de vários cursos de mestrados profissionais em administração pública no último quinquênio chame a atenção, justificados pela alta da demanda de capacitação do corpo técnico governamental e do terceiro setor e das próprias universidades públicas, o número de 13 programas de pós-graduação exclusivos em administração pública e sete com área de concentração e/ou linha de pesquisa nesse campo de saber é diminuto na área de avaliação de administração e ciências contábeis. Para efeito de comparação, os registros da Capes somam 139 programas de pós-graduação em $2014,{ }^{7}$ sendo 118 de administração (inclusive os de administração pública) e 21 de contabilidade, subdivididos em 36 programas de mestrado acadêmico, 57 programas de mestrado profissional e 46 programas com mestrado acadêmico e doutorado.

Alguns especialistas alegam que se devem contabilizar, na comunidade epistêmica de administração pública no Brasil, os grupos de pesquisa perenes nesse campo, que estão espalhados pelos demais programas de mestrado e doutorado em administração. Sem dúvida, esse argumento faz todo o sentido. Nesse caso, por exemplo, adentrariam no rol de programas de pós-graduação em administração pública algumas IES como Fearp-USP, PUC-PR, PUC-SP, USCS, UFMG, UFRGS, UFSC e Unifacs, as quais mantêm atuantes grupos de pesquisa que

\footnotetext{
${ }^{6}$ É patente a importância da EBAPE/FGV e da EAUFBA para a construção do campo de saber da administração pública no Brasil. No âmbito deste artigo essa relevância é visível nos quadros da seção 2, os quais indicam os docentes dessas IES se revezando na coordenação da área (ou divisão acadêmica) de Administração Pública da ANPAD desde sua criação em 1985.

${ }^{7}$ Desses 139 programas recomendados pela Capes na área de avaliação de administração e ciências contábeis, 97 estão filiados como membros efetivos da ANPAD na atualidade; a listagem dos programas associados encontra-se disponível em: <www.anpad.org.br>. Além disso, cabe registrar que, ao pé da letra, a área da Capes intitula-se Administração, Ciências Contábeis e Turismo. Porém, para efeito do processo de avaliação, ela se subdivide em duas áreas: de um lado, a de administração, que inclui também os programas de pós-graduação em ciências contábeis e mesmo de administração pública; e, do outro lado, a de turismo — com oito cursos de mestrado e um de doutorado.
} 
produzem dissertações, teses e artigos sobre a temática de gestão pública. No entanto, esse alargamento do perímetro da área não desfaz a condição, em termos proporcionais, de baixa institucionalização de cursos de mestrado e doutorado em tal campo de saber no país.

Não se pode olvidar também dos programas de pós-graduação em gestão/políticas pública(s) que são oferecidos em outras áreas de avaliação da Capes. Existem diversos mestrados e doutorados nas áreas interdisciplinar e de ciência política que interagem com subáreas da administração pública. O quadro 5 enumera 14 programas nessas duas áreas de avaliação que, além de adotar a nomenclatura, explicitamente se apoiam em macrotemas de administração pública em suas áreas de concentração ou linhas de pesquisa.

$$
\text { Quadro } 5
$$

\section{Programas de pós-graduação stricto sensu em gestão/políticas pública(s), nas áreas de avaliação interdisciplinar e de ciência política, em 2014*}

\begin{tabular}{|c|c|c|c|}
\hline \multicolumn{4}{|c|}{ Programas de Pós-Graduação em Gestão/Políticas Pública(s), na área de avaliação Interdisciplinar } \\
\hline & IES & Programa & Nível \\
\hline 1 & UFBA & Programa de Pós-Graduação em Gestão Social & Mestrado Profissional \\
\hline 2 & UERJ & Programa de Pós-Graduação em Políticas Públicas & Mestrado e Doutorado \\
\hline 3 & UFC & Programa de Pós-Graduação em Avaliação de Políticas Públicas & Mestrado Profissional \\
\hline 4 & UFPE & Programa de Pós-Graduação em Gestão Pública & Mestrado Profissional \\
\hline 5 & UFPR & Programa de Pós-Graduação em Políticas Públicas & Mestrado e Doutorado \\
\hline 6 & UFRJ & $\begin{array}{l}\text { Programa de Pós-Graduação em Políticas Públicas, Estratégia e } \\
\text { Desenvolvimento }\end{array}$ & Mestrado e Doutorado \\
\hline 7 & UMC & Programa de Pós-Graduação em Políticas Públicas & Mestrado Acadêmico \\
\hline 8 & Unesp & Programa de Pós-Graduação em Planejamento e Análise de Políticas Públicas & Mestrado Profissional \\
\hline 9 & Unifal & Programa de Pós-Graduação em Gestão Pública e Sociedade & Mestrado Acadêmico \\
\hline 10 & Univali & Programa de Pós-Graduação em Gestão de Políticas Públicas & Mestrado Profissional \\
\hline \multicolumn{4}{|c|}{ Programas de Pós-Graduação em Gestão/Políticas Pública(s), na área de avaliação de Ciência Política } \\
\hline & IES & Programa & Nível \\
\hline 11 & UEM & Programa de Pós-Graduação em Políticas Públicas & Mestrado Profissional \\
\hline 12 & UFABC & Programa de Pós-Graduação em Políticas Públicas & Mestrado Acadêmico \\
\hline 13 & UFPE & Programa de Pós-Graduação em Políticas Públicas & Mestrado Profissional \\
\hline 14 & UFRB & Programa de Pós-Graduação em Gestão de Políticas Públicas & Mestrado Profissional \\
\hline
\end{tabular}

Fonte: Elaboração própria, baseada na relação dos cursos recomendados pela Capes nas áreas de avaliação Interdisciplinar e de Ciência Política (2014).

*Existem outros cursos na área Interdisciplinar que se utilizam do nome de Gestão/Políticas Pública(s), mas não têm um diálogo tão nítido com a AP. 
Na área de avaliação Interdisciplinar da Capes, cinco dos 10 programas de pós-graduação em gestão/políticas pública(s) são mestrados profissionais voltados para funcionários públicos e gestores de organizações da sociedade civil. Naturalmente, os cursos de mestrado e doutorado de tal área apresentam um corpo docente multidisciplinar oriundo de áreas de conhecimento que perfazem o campo de saber em administração pública como: administração, ciências sociais, economia e direito. Na área de avaliação de ciência política, são três mestrados profissionais e um mestrado acadêmico que tem como referencial teórico a análise de políticas públicas. É válido destacar que metade das 14 IES citadas no quadro 5 oferta também cursos de graduação no Campo de Públicas. Na UFABC e na Unifal, por exemplo, os projetos de pós-graduação que originaram os cursos de mestrado são desdobramentos dos cursos de bacharelado.

Em outras áreas de avaliação da Capes como planejamento urbano e regional, serviço social, economia e sociologia, ainda que a relação com o campo de saber em administração pública seja mais distante, encontram-se alguns programas de pós-graduação que fazem uso das nomenclaturas de gestão/políticas pública(s) que, além de ilustrarem a apropriação pluridisciplinar desses termos, se integram com a administração pública por tratarem de temas circunvizinhos. Eis alguns exemplos:

、 Na área de planejamento urbano e regional, a Universidade Federal do Tocantins (UFT) oferece um mestrado profissional em gestão de políticas públicas. Ademais, governança territorial e serviços públicos são linhas de pesquisa nos programas de pós-graduação que referenciam a área;

v Na área de avaliação de serviço social, a Universidade Federal do Maranhão (UFMA) oferece o Programa de Pós-Graduação em Políticas Públicas com os cursos de mestrado acadêmico e doutorado - nota 6 na Capes — com área de concentração em gestão de políticas sociais;

、 Na área de economia, o Ipea, órgão de apoio ao planejamento governamental e reconhecido think tank de políticas públicas, oferece o mestrado profissional em políticas públicas e desenvolvimento e edita o periódico Planejamento e Políticas Públicas (PPP); e,

v Na área de sociologia, a Universidade Estadual do Ceará (Uece) oferece o mestrado acadêmico em políticas públicas e sociedade, bem como o mestrado profissional em planejamento e políticas públicas.

Outro vetor importante no sistema de educação superior em AP, sobretudo na área de treinamento e desenvolvimento (T\&D), é o das escolas de governo, voltadas para o processo de aperfeiçoamento e (re)qualificação de funcionários públicos a partir da oferta de cursos livres, de especialização e de mestrado profissional. Em nível federal, cita-se o exemplo da Escola Nacional de Administração Pública (Enap), Escola Superior de Administração Fazendária (Esaf), Instituto Rio Branco, Centro de Formação da Câmara dos Deputados (Cefor) etc. Em nível estadual, evidencia-se o caso da Fundação João Pinheiro em Minas Gerais (a única a ofertar curso de graduação em administração pública), da Fundap em São Paulo, das escolas 
de contas dos diversos Tribunais de Contas Estaduais (TCEs), dos Institutos dos Legislativos Estaduais, dentre outras. Sabidamente, a presença de algumas dessas escolas de governo no Brasil é de extrema importância na produção de estudos e materiais didáticos no campo de saber em administração pública, como é o caso da Enap. Algumas, como Esaf e Cefor, já possuem seus próprios cursos de mestrado profissional: a primeira com três programas de pós-graduação - economia do setor público, orçamento público e gestão pública - em parceria com a UnB; e a segunda com o Programa de Pós-Graduação em Poder Legislativo.

Para um aprofundamento sobre o papel das escolas de governo no ensino de administração pública no Brasil, um dos trabalhos de fôlego é a tese de doutorado de Nicolini (2007), a qual mostra como algumas dessas instituições configuram-se como universidades corporativas do setor público voltadas: (a) para a aprendizagem de funcionários com investidura nas carreiras típicas de Estado; e (b) para a capacitação de quadros técnicos para os projetos governamentais estratégicos. Em adição, um quadro das escolas de governo em operação no país e uma radiografia da sua oferta de capacitação estão disponíveis no site da Rede Nacional de Escolas de Governo, coordenada pela Enap; são, atualmente, em torno de 200 instituições públicas dos poderes Executivo, Legislativo e Judiciário, presentes nas esferas federal, estadual e municipal.

\section{Overview dos grupos de pesquisa, principais congressos e periódicos no campo de saber em administração pública no Brasil}

Para uma análise de quaisquer áreas de conhecimento ou campos de saber, sabe-se que o sistema de pesquisa, associado ao sistema de ensino, sobretudo no nível de pós-graduação, tem influência categórica sobre o volume, o conteúdo e a qualidade da produção acadêmica. Logo, a existência de maior ou menor quantidade de programas de mestrado e doutorado com ênfase em administração pública, a constituição e o funcionamento de grupos de pesquisa especializados em suas temáticas e a existência de eventos e periódicos exclusivos são determinantes do estágio atual desse campo de saber no país.

No tocante aos grupos de pesquisa em administração pública no país, o levantamento realizado no Diretório dos Grupos de Pesquisa no Brasil do CNPq (<http://dgp.cnpq.br >) na área de administração, utilizando-se da palavra-chave administração pública com variações para gestão pública e políticas públicas, resultou em 173 ocorrências, referentes a fevereiro de 2013. Aproximadamente $50 \%$ desses grupos de pesquisa pertencem à IES de cinco unidades da federação (MG, SP, RJ, BA e DF) e seus pesquisadores - majoritariamente — são docentes dos programas de pós-graduação listados no quadro 4. Quando se utiliza a palavra-chave administração pública com variação para gestão pública para localizar grupos de pesquisa nas áreas de ciência política, planejamento urbano e regional, economia, serviço social e sociologia, o resultado, respectivamente, é: 24, 19, 22, 20 e 25. Todavia, como o termo gestão pública é empregado de forma errática - em parte, pela não diferenciação entre public management 
e public affairs na língua portuguesa —, sua identificação no título desses grupos de pesquisa não garante uma acepção e abordagem dos temas de administração pública.

Atinentes aos eventos com programação científica de administração pública, existem os acadêmicos e os profissionais. Em nível nacional, o Encontro de Administração Pública e Governo (EnAPG) promovido pela ANPAD e o EnANPAD com os trabalhos da Divisão Acadêmica de APB destacam-se como eventos acadêmicos, complementados pelo já tradicional Colóquio Internacional sobre Poder Local, realizado pelo Ciags da UFBA. Nos últimos anos, o Encontro Nacional de Pesquisadores em Gestão Social (Enapegs) contribui com a produção científica de administração pública com artigos que discutem as inter-relações entre gestão/políticas pública(s) e sociedade civil, como demostram Mendonça, Gonçalves-Dias e Junqueira (2012). Para a graduação, há o evento promovido pela Federação Nacional dos Estudantes dos Cursos do Campo de Públicas (Feneap), denominado Eneap e realizado, anualmente, desde 2002. Entre os eventos profissionais, que também incluem a participação de professores e pesquisadores, sobressai-se o Congresso do Consad de Gestão Pública, promovido pelo Conselho Nacional de Secretários de Estado de Administração.

No âmbito internacional, destaca-se o encontro organizado pela International Research Society for Public Management — IRSPM Conference. Ademais, citam-se os eventos: (a) Academy of Management, que possui uma seção dedicada ao debate sobre administração pública; (b) o evento promovido pela American Society for Public Administration (Aspa); (c) o congresso da European Group for Public Administration (EGPA); e, (d) o congresso da Iberoamerican Academy of Management. Na América Latina, o destaque é para o Congresso Internacional do Centro Latino-Americano de Administração para o Desenvolvimento (Clad), um evento profissional, mas que inclui os acadêmicos e versa sobre reforma do Estado e da administração pública. Em 2014, realiza a sua XIX edição.

Todos esses eventos nacionais e internacionais supracitados são anuais, exceto: o EnAPG e o evento da Iberoamerican Academy of Management, realizados bienalmente, o primeiro nos anos pares e o segundo, nos anos impares; e o Colóquio Internacional sobre Poder Local, realizado trienalmente (cuja última edição, de número XII, ocorreu em 2012). Em linhas gerais, os eventos acadêmicos nacionais comportam e/ou absorvem o volume atual da produção científica doméstica em administração pública. Por sua vez, os eventos acadêmicos internacionais ainda são pouco frequentados pelos pesquisadores brasileiros, em que pese o crescimento da presença de alguns líderes de grupos de pesquisa nacionais no IRSPM no último quinquênio.

No que corresponde aos periódicos, como veículo nacional de publicação de artigos sobre administração pública cabe destacar a Revista de Administração Pública (RAP), fortemente dedicada aos artigos do campo e editada desde 1967. Não se pode desconsiderar a revista Organizações \& Sociedade (O\&S), que tem um escopo editorial um pouco mais amplo, mas tem entre seus focos de publicação os temas de gestão pública. Nos dias atuais, a RAP e a O\&S são as revistas nacionais com espectro de administração pública mais bem qualificadas pelo Sistema Qualis/Capes de avaliação de periódicos, na área de avaliação de administração. Em termos de antiguidade, cita-se a Revista do Serviço Público, criada em 1937 pelo Dasp. A 
periodicidade varia desde o primeiro ano de circulação e a publicação foi interrompida entre 1975-80 e 1990-93. Em 1998 foi reestruturada pela Enap e valoriza a contribuição de funcionários públicos a partir de reflexões aplicadas, estudos de casos e relatos de práticas.

Há ainda periódicos nacionais mais recentes que se orientam declaradamente para as temáticas da administração pública, tal como faz a RAP, assim como outros que publicam artigos de administração pública, mas dividem seu espaço editorial com assuntos conexos das ciências administrativas, tal como faz a O\&S. O quadro 6 elenca as revistas nacionais pontuadas na área de avaliação de administração que são específicas de administração pública ou que abarcam enfaticamente a produção acadêmica desse campo de saber.

\section{Quadro 6}

Periódicos nacionais de administração pública ou com escopo editorial que enfatiza os temas de gestão pública, na área de avaliação de administração, em 2014

\begin{tabular}{|c|c|c|c|c|}
\hline \multicolumn{5}{|c|}{ Periódicos nacionais declaradamente de administração pública } \\
\hline & & Periódico & IES que edita & Periodicidade \\
\hline 1 & A2 & Revista de Administração Pública (RAP) & FGV-RJ & bimestral \\
\hline 2 & B3 & Administração Pública e Gestão Social (APGS) & UFV & trimestral \\
\hline 3 & B3 & Cadernos Gestão Pública e Cidadania (CGPC) & FGV-SP & semestral \\
\hline 4 & B3 & Gestão Pública: práticas e desafios & UFPE & semestral \\
\hline 5 & B4 & Revista do Serviço Público (RSP) & ENAP & trimestral \\
\hline 6 & B4 & Revista Gestão \& Políticas Públicas (RGPP) & USP & semestral \\
\hline 7 & B5 & Temas de Administração Pública (TAP) & UNESP & semestral \\
\hline \multicolumn{5}{|c|}{ Periódicos nacionais não exclusivos de AP, mas que abarcam os temas de gestão pública } \\
\hline & & Periódico & IES que edita & Periodicidade \\
\hline 8 & A2 & Organizações \& Sociedade (O\&S) & UFBA & trimestral \\
\hline 9 & B1 & Cadernos EBAPE.BR & FGV-RJ & trimestral \\
\hline 10 & B1 & Gestão \& Regionalidade (G\&R) & USCS & quadrimestral \\
\hline 11 & B2 & Gestão \& Planejamento (G\&P) & UNIFACS & quadrimestral \\
\hline 12 & B3 & Gestão e Sociedade (GeS) & UFMG & quadrimestral \\
\hline 13 & B4 & Revista Brasileira de Administração Política (RBAP) & UFBA & semestral \\
\hline 14 & B5 & Cadernos de Gestão Social (CGS) & UFBA & semestral \\
\hline 15 & B5 & NAU Social & UFBA & semestral \\
\hline
\end{tabular}

Fonte: Elaboração própria, baseada na relação dos periódicos indicados no WebQualis de administração pela Capes e pontuados entre os estratos A1 e B5 (2014). 
Assinala-se que nos estratos mais significativos do Qualis, periódicos classificados como A1, A2 e B1, apenas a RAP figura como revista declaradamente de administração pública. Incluindo os periódicos que consideram a produção acadêmica em administração pública, mas não de maneira exclusiva, acrescenta-se a O\&S, o Cadernos EBAPE.BR e a G\&R. Mais uma vez, é notável o papel da FGV-RJ e da UFBA para o campo de saber em administração pública no país, nesse caso, como instituições de ensino que editoram as principais publicações nacionais que amparam a produção acadêmica de gestão pública.

É clarividente nesse pool de revistas exclusivas de administração pública, além do número reduzido de veículos para publicação, que faltam periódicos no estrato intermediário (B2). Algumas revistas, inclusive, estão mais bem qualificadas na área de avaliação de ciência política do que na área de avaliação de administração, a saber: RSC, RGPP e TAP. A Revista do Serviço Público, por exemplo, é B2 no Sistema Qualis de ciência política e B4 no WebQualis de administração.

Diante desse quadro restrito de periódicos tipicamente de AP, urge estimular a criação de novas revistas, função essa que deve ser desempenhada pelos demais centros de ensino e pesquisa em administração pública, relacionados no quadro 4, que ainda não editoram uma publicação específica nesse campo de saber. Assim, FJP, UnB, UFRN, Udesc e Ufla são IES com tradição em administração pública que podem seguir o exemplo de escolas como FGV-SP, UFV, UFPE, USP e Unesp que conceberam veículos próprios para a temática de gestão pública no último quinquênio. Neste sentido, a iniciativa da UFBA de lançar três novas revistas RGS, RBAP e Nau Social —, afora a publicação da O\&S, é bastante louvável.

Nesse estímulo para a criação de novos periódicos de AP no país, é salutar o incentivo para o surgimento também de revistas para divulgar a produção tecnológica, procedente dos mestrados profissionais; como demonstrado no quadro 4, essa modalidade de pós-graduação profissionalizante é a alavanca de crescimento da pós-graduação em AP no Brasil e, ainda, carece de veículos específicos para a difusão de seus trabalhos.

Pode-se até argumentar que, no WebQualis da área de administração, existem diversas revistas editoradas por associações e programas de pós-graduação (exemplos: RAC, BAR, RAE, Rausp, REAd, RCA etc.) e inúmeros periódicos oriundos de outras áreas de avaliação da Capes (exemplos: Dados, Revista Brasileira de Ciências Sociais e Lua Nova, da área de ciência política) que se posicionam como A2 ou B1 e acatam artigos de gestão pública. Entretanto, os textos de AP são esporádicos nessas publicações e, por conseguinte, a comunidade acadêmica não se identifica com esses veículos para sua interlocução.

No âmbito internacional, a base do Journal of Citation Reports (JCR) oferece um ranking dos periódicos mais citados e com maior relevância para a comunidade acadêmica de mais de 60 disciplinas por meio do fator de impacto. Os 12 mais bem colocados na disciplina de Public Administration, referente a fevereiro de 2013, em ordem decrescente, são:

\section{Journal of Policy Analysis and Management;}

2. Journal of Public Administration Research and Theory;

3. International Public Management Journal; 
4. Governance;

5. Journal of European Social Policy;

6. Policy Sciences;

7. Philosophy \& Public Affairs;

8. Review of Policy Research;

9. Public Management Review;

10. Policy Studies Journal;

11. Public Administration Review; e

12. Environment and Planning Government and Policy.

Entre essas revistas, as mais bem classificadas pelo Sistema Qualis são a Public Management Review, A1 na área de avaliação da ciência política e A2 na área de administração, e a Public Administration Review, A1 na área de ciência política. Considerando outros periódicos internacionais exclusivos de AP e constantes no WebQualis de administração, encontram-se: no estrato A1, Government Information Quarterly, International Journal of Public Sector Management e Public Choice; e, no estrato A2, American Review of Public Administration, Local Government Studies e Public Administration and Development. No estrato B1, além do periódico Journal of Public Affairs, acha-se o periódico latino-americano, editorado em língua espanhola, mais bem qualificado pela Capes, qual seja: Gestión y Políticas Publicas, uma publicação da Divisão de Administração Pública do Centro de Investigación y Docencia Económicas (Cide) do México.

Decerto, a pequena presença das mais importantes publicações internacionais de Public Administration no Sistema Qualis da Capes, na área de avaliação de administração, é mais um forte indício da ínfima internacionalização da comunidade acadêmica de administração pública brasileira, algo também captado pelos eventos internacionais. Aumentar a presença no debate acadêmico de administração pública em nível internacional, seja nos congressos, seja nos periódicos, é um dos grandes desafios para os pesquisadores nacionais nesta década.

\section{5. À guisa de conclusão}

Este artigo descreve e analisa, a partir do trabalho do Comitê Científico de APB da ANPAD no quadriênio 2009-12 e da sua interlocução com a comunidade epistêmica da área no Brasil, alguns dos aspectos que configuram esse campo de saber no país:

จ o percurso da administração pública como área na ANPAD;

\ a conjuntura da educação superior nacional em AP, destacando-se a pós-graduação; e

v e o quadro recente do sistema doméstico de divulgação científica na área. 
Inegavelmente, a sistematização e o exame de informações relativas a esses aspectos indicam o estado da arte do campo de saber em administração pública no Brasil e descortinam alguns de seus avanços, lacunas e desafios na atualidade.

No âmbito da ANPAD, observam-se avanços quantitativos na produção acadêmica da área de AP ao longo da última década. Sem embargo, uma das lacunas é a dispersão dos artigos; na última década, a área tornou-se aberta a todo e qualquer trabalho, desde que seu objeto de estudo abordasse o setor público. Como desafio, vale persistir na demarcação da divisão acadêmica de APB a partir de temas que lhe confiram uma identidade, como parte da tarefa maior de toda a academia de AP do país de fortalecê-la como campo disciplinar.

Perante a área de conhecimento de administração no Brasil, o campo de saber em administração pública é considerado, historicamente, uma subárea (ou habilitação) e reduzido à aplicação dos modelos de gestão (ou áreas funcionais) ao setor público. De modo semelhante, com relação às áreas das ciências humanas nas quais se apoia, como a ciência política, a economia, o direito, a sociologia ou mesmo a filosofia, a administração pública não se posiciona no mesmo patamar. E, muitas vezes, ao tentar se igualar pela adoção dos objetos de estudo dessas áreas de conhecimento, perde sua especificidade. Nas palavras de Pacheco (2013), “(...) a comunidade de AP no país, ao emprestar indiscriminadamente questões de pesquisa da Ciência Política [por exemplo], pode deixar de lado aspectos fundamentais do funcionamento do Estado por dentro”. E Cavalcanti (2013) completa: “(...) distintamente das outras áreas, a Administração Pública é por demais permeável e permissiva, sendo recorrentemente invadida [e descaracterizada] por quaisquer trabalhos que mencionem o Estado [por exemplo]". ${ }^{8}$ Ou seja, a administração pública ainda carece de um corpo e de espaço próprios no país. E, sem dúvida, a construção desses elementos deve ser um esforço constante do Comitê Científico e dos Líderes de Tema de APB nos EnANPADs e EnAPGs.

No que concerne à educação superior em administração pública no país, embora verificado um aumento dos cursos de graduação e obtido o reconhecimento desses bacharelados como Campo de Públicas - com DCNs homologadas pelo MEC —, perfazendo um avanço para o campo de saber, ainda é baixa a institucionalização dos programas de pós-graduação em administração pública do tipo puro sangue na área de administração da Capes, na qual se avista tão somente um curso de doutorado e três cursos de mestrado acadêmicos. Percebe-se, adicionalmente, que apesar de uma ampliação do locus da pós-graduação em administração/ gestão/políticas pública(s) para as áreas interdisciplinar e de ciência política da Capes, inexiste uma integração ou, ao menos, um diálogo entre esses cursos no Brasil.

Nessa conjuntura, um dos desafios que se sobressai é a aproximação institucional dos programas de pós-graduação (e grupos de pesquisa) em administração pública da área de administração, em busca de uma maior relevância e representatividade do campo de saber em

\footnotetext{
${ }^{8}$ Excertos das exposições dos professores Regina Pacheco (FGV-SP) e Bianor Cavalcanti (FGV-RJ) na abertura do I Encontro Brasileiro de Administração Pública, realizado na UFRN, em Natal, no ano de 2013.
} 
AP diante da Capes e da própria ANPAD. Em outras palavras, urge diminuir a fragmentação histórica da AP como campo disciplinar na pós-graduação no país, a partir de reflexões e ações conjuntas acerca:

- da especificidade da produção acadêmica de AP e de sua valorização perante as agências federais (exemplo: CNPq e Finep) e estaduais de fomento à pesquisa;

v da (re)discussão dos critérios de avaliação dos seus programas de pós-graduação;

v da pertinência da criação de uma subárea de AP — tal como é o turismo — na área de avaliação de administração da Capes, ou mesmo de uma nova área de administração/gestão/ políticas pública(s) na grande área de ciências sociais aplicadas;

จ de estratégias coletivas de interlocução com o setor público nacional e com pesquisadores no exterior, visando colaborações/parcerias que favoreçam o desenvolvimento científico e tecnológico do campo; e

v do fortalecimento dos meios de divulgação científica disponíveis para o campo. ${ }^{9}$

Correspondente a esta última questão, que envolve os eventos e periódicos, cabe frisar que a seção 4 desvelou que os três maiores desafios do campo de saber em administração pública no Brasil são: (a) incentivar fortemente a internacionalização dos pesquisadores, a qual é comprovadamente pequena - veja a desconsideração dos principais periódicos internacionais de AP no Sistema Qualis; (b) a necessidade de (re)valorização de alguns periódicos exclusivos de AP no WebQualis da área de avaliação de administração (p. ex.: a Revista do Serviço Público); e (c) a criação de revistas nacionais tipicamente de AP, incluindo algumas com desígnio editorial tecnológico para absorver a produção acadêmica dos mestrados profissionalizantes que surgiram no campo.

Enfim, espera-se que este balanço, ao cotejar alguns dos aspectos que marcam — historicamente - a organização da administração pública como campo de saber no Brasil, com o trajeto hodierno do Comitê Científico de APB da ANPAD, ajude a retomar e subsidiar o debate nacional sobre os caminhos da administração pública como disciplina autônoma, com identidade própria, estratégica para o exercício profissional da gestão pública e, desta forma, para o desenvolvimento do próprio país. Assim, apresenta-se também como um convite a todos os pesquisadores da comunidade acadêmica de AP no Brasil para essa empreitada.

\footnotetext{
${ }^{9}$ Promover de maneira congregada esses e outros debates sobre os rumos da pós-graduação em administração pública no país, nos próximos anos, é um dos papéis a que se propõe a recém-fundada Sociedade Brasileira de Administração Pública (SBAP), lançada em 2013 e em fase de organização e implantação ao longo de 2014.
} 


\section{Referências}

ANPAD. Anais dos EnANPADs - IX ao XXXVII.

ANPAD. Anais dos EnAPGs - I, II, III, IV e V.

CAPES. Cursos recomendados/reconhecidos. Disponível em: <www.capes.gov.br/cursos-recomendados >. Acesso em: 24 fev. 2014.

CNE. Resolução no 1, de 13 de janeiro de 2014. Institui as Diretrizes Curriculares Nacionais do curso de graduação em Administração Pública, bacharelado, e dá outras providências.

CNPq. Disponível em: <http://dgp.cnpq.br>. Acesso em: 28 fev. 2014.

COELHO, Fernando de S. Radiografia do ensino de graduação em administração pública no Brasil (1995-2006). In: ENCONTRO DA ASSOCIAÇÃO NACIONAL DOS PROGRAMAS DE PÓS-GRADUAÇÃO, 2008. Anais... Rio de Janeiro: ANPAD, 2008. p. 1-16.

COELHO, Fernando de S.; NICOLINI, Alexandre M. Do auge à retração: análise de um dos estágios de construção do ensino de administração pública no Brasil (1966-1982). Revista Organizações \& Sociedade, v. 20, n. 66, p. 403-422, jul./set. 2013.

COELHO, Fernando de S.; OLENSCKI, Antonio B.; CELSO, Rafael P. Da letargia ao realento: notas sobre o ensino de graduação em administração pública no Brasil no entremeio da crise do Estado e da redemocratização no país (1983-1994). Rev. Adm. Pública, Rio de Janeiro, v. 45, n. 6, p. $1707-$ 1732, nov./dez. 2011.

FACHIN, Roberto C. Construindo uma associação científica: 30 anos da ANPAD — memórias, registros e desafios. Rio de Janeiro: ANPAD, 2006.

FADUL, Elvia; MAC-ALLISTER DA SILVA, Mônica. Limites e possibilidades disciplinares da administração pública e dos estudos organizacionais. In: ENCONTRO DA ASSOCIAÇÃO NACIONAL DOS PROGRAMAS DE PÓS-GRADUAÇÃO, 2008. Anais... Rio de Janeiro: ANPAD, 2008. p. 351-365.

FADUL, Elvia; MAC-ALLISTER DA SILVA, Mônica; SILVA, Lindomar P. da. Ensaiando interpretações e estratégias para o campo da administração pública. Rev. Adm. Pública, Rio de Janeiro, v. 46, n. 6, p. 1437-1458, nov./dez. 2012.

FADUL, Elvia; SILVA, Lindomar P. da; CERQUEIRA, Lucas S. Análise do campo da administração pública através da produção científica publicada nos anais dos ENAPGs. Cadernos Gestão Pública e Cidadania, São Paulo, v. 16, n. 59, p. 151-166, jul./dez. 2011.

FARAH, Marta F. S. Administração pública e políticas públicas. Ver. Adm. Pública, Rio de Janeiro, v. 45, n. 3, p. 813-836, maio/jun. 2011.

FISCHER, Tânia. O ensino de administração pública no Brasil: os ideais de desenvolvimento e as dimensões de racionalidade (1948-1984). Tese (doutorado) — Faculdade de Economia e Administração, Universidade de São Paulo, São Paulo, 1984. 
LUSTOSA DA COSTA, Frederico. Reforma do Estado e contexto brasileiro: crítica ao paradigma gerencialista. Rio de Janeiro: Ed. FGV, 2010.

LUSTOSA DA COSTA, Frederico. Reforma do Estado em novas perspectivas: lições da experiência brasileira. Perspectivas em Políticas Públicas, Belo Horizonte, v. 1, n. 1, p. 203-212, jan./jun. 2008.

MENDONÇA, Patrícia Maria E.; GONÇALVES-DIAS, Sylmara L. F.; JUNQUEIRA, Luciano A. Prates. Gestão social: notícias sobre o campo de estudos e práticas a partir das interações e debates do VI Enapegs. Rev. Adm. Pública, Rio de Janeiro, v. 46, n. 5, p. 1391-1408, set./out. 2012.

MEZZOMO KEINERT, Tânia M. Administração pública no Brasil: crises e mudanças de paradigmas. São Paulo: Anablume; Fapesp, 2000.

NICOLINI, Mendes A. Aprender a governar: a aprendizagem dos dirigentes públicos para as carreiras de Estado. Tese (doutorado) - Escola de Administração, Universidade Federal da Bahia, Salvador, 2007.

PACHECO, Regina S. Administração pública nas revistas especializadas — Brasil, 1995-2002. Revista de Administração de Empresas, São Paulo, v. 43, n. 4, p. 63-71, out./dez. 2003.

VENDRAMINI, Patrícia. Análise do Curso de Administração Pública da UDESC-ESAG à luz das competências. Tese (doutorado) — Escola de Administração, Universidade Federal da Bahia, Salvador, 2013.

Élvia Fadul é coordenadora do Programa de Pós-Graduação em Administração da Universidade de Salvador (Unifacs).E-mail: elvia@unifacs.br.

Fernando de Souza Coelho é professor do Programa de Pós-Graduação em Gestão de Políticas Públicas da Universidade de São Paulo (USP). E-mail: fernandocoelho@usp.br.

Frederico Lustosa da Costa é professor do Programa de Pós-Graduação em Administração da Universidade Federal Fluminense (UFF). E-mail: fredlustosa@gmail.com.

Ricardo Corrêa Gomes é professor do Programa de Pós-Graduação em Administração da Universidade de Brasília (UnB). E-mail: gomesic.rg@gmail.com. 